\title{
TWO OPPOSITE POLES ATTRACTED BY COMMON \\ SCIENTIFIC AND HUMANISTIC INTERESTS: \\ INTERVIEW WITH PROF. BASILIO \\ VALLADARES HERNÁNDEZ
}

Basilio Valladares Hernández is Honorary Professor at the University of La Laguna, founder and alma mater of the Instituto Universitario de Enfermedades Tropicales y Salud Pública de Canarias, as well as of the Fundación Canaria para el Control de Enfermedades Tropicales (FUNCCET). Awarded in 2017 by the Canary Islands Government with its Golden Medal, his exceptional career devoted to research has made of him an internationally reputed scientist.

Prof. Valladares Hernández is certainly an extraordinary figure who deserves our admiration and respect, but this interview obeys to his close relationship with Prof. Gómez Soliño, two opposite poles attracted by common scientific and humanistic interests.

Eds.: It might seem unusual to find a philologist as a member of a foundation for the control of tropical diseases like the FUNCCET, as unusual as the collaboration maintained for years between a hard scientist, an awarded parasitologist in your case, and a linguist such as Prof. Gómez Soliño. How was this relationship born?

V.B.: The FUNCCET has among its objectives to disseminate knowledge about tropical diseases, but also about science and culture in general with the aim of improving life conditions in underdeveloped countries. Anyone concerned about the life of those in need has room in the foundation.

But, our collaboration started many years ago. In 1998 we took the first steps to create the Instituto Universitario de Enfermedades Tropicales y Salud Pública de Canarias (University Institute of Tropical Diseases and Canarian Public Health). In 1999 Prof. Gómez Soliño was elected Rector of the ULL and his contribution to the successful completion of the administrative process to create the Institute -going through different establishments: Ministerio de Educación y Ciencia, Consejo de Universidades, Consejo Cientifico Nacional, Consejo Universitario de la Comunidad Autónoma, among otherswas decisive. It took three years to create the Institute, which was formally established in March 2001. In its $10^{\text {th }}$ anniversary we acknowledged and awarded the persons who had strongly and clearly supported both the

DOI: https://doi.org/10.25145/j.recaesin.2020.80.10

Revista Canaria de Estudios Ingleses, 80; April 2020, pp. 173-176; ISSN: e-2530-8335 
creation and improvement of the Institute, and among them was Prof. Gómez Soliño. When in 2013 the FUNCCET was started we asked him to form part of its Patronage and he kindly accepted.

Eds.: Which do you think have been the main contributions of Prof. Gómez Soliño in the Foundation?

V.B.: Well, many and varied. He is a man with a grand imagination and creativity, a constant provider of ideas for the improvement of the Institute's work. He analyzed what we were doing in Peru and some African countries and he paved the way for us to work in Cabo Verde. But his most important contribution has been instituting the international seminars of CampusÁfrica celebrated every two years under the auspice of the University of La Laguna and organized by the FUNCCET.

Eds.: What has CampusÁfrica meant to the Canary Islands and The University of La Laguna?

V.B.: CampusÁfrica brings to the Canary Islands a considerable group of students with the best academic records from different African universities - especially from those closest to us- as well as an important number of international first line professors in the areas of health sciences, culture, economics and politics. The Canary Islands and the ULL are for a few days the center of knowledge for development. As a consequence, some of the grant holders attending CampusÁfrica, will later continue their postgraduate studies in our university; on the other hand, ULL teachers find the opportunity to get in contact with relevant figures in the field of knowledge for development projects that are advantageous for everyone.

Eds.: Which would you consider the main achievements of the work done in Cabo Verde?

V.B.: A laboratory of Immunology and Molecular Biology has been created in Cabo Verde, which, in turn, will soon allow for the creation of a Biomedicine Institute in the Public University of Cabo Verde. Additionally, in this same University, different specialization courses, in diverse fields, have been held, the latest of them, "Macaronesia Campus Global", in October 2019. This is leading the Canary Islands and the ULL to become a referent for the development of the country; meanwhile, the collaboration among scholars through various projects is rendering beneficial results for both archipelagos.

Eds.: You both have been internationally awarded, receiving in 2016 the first class medal of scientific knowledge granted by Cabo Verde's government because of the role you have played in promoting and stimulating higher education in this country. But, quite often it seems the work we do at our university is not so well acknowledged. How would you evaluate the goals achieved in these years? Do you consider they have received deserved recognition? 
V.B.: Many important things have certainly been achieved and this makes you feel quite gratified. Prof. Gómez Soliño can be satisfied of the work done. The truth is that, internationally and, generally speaking, out of the university, it seems that the work that is being developed is well received and acknowledged. As a proof Prof. Gómez Soliño was granted last year the Premio Canarias de Internacionalización. In our university, we have gone through, let's say, some "uncomfortable moments" in the last few years but with the recent changes we hope everything will come back to normal.

About the last question, I want to state, that all the work we do is done without asking or expecting any returns; it feels good, though, to receive some acknowledgement; if not, simply avoiding intrusion from those unable to do anything but disturb, obstruct or destroy the work of others, would be enough.

Eds.: In a more comprehensive scope, which do you think is Prof. Gómez Solińo's main contribution to the ULL?

V.B.: Many have been his contributions along his extensive academic life. First I would underline he has been a great teacher and his students have constantly acknowledged it. Through his academic life he has been absolutely devoted to broadening and opening the ULL to better serve the Canarian society. As a Rector he enhanced the infrastructures of the ULL through a negotiation with the, by then, financial institution, CajaCanarias. As a result, two completely equipped study-rooms buildings were constructed, one in Guajara Campus and the other in Anchieta Campus. In the same line, he was always concerned with the improvements of the ULL Library. He also paid attention to other scientific infrastructures giving impulse to the Centro de Estudios Africanos, the Instituto Universitario de Enfermedades Tropicales y Salud Pública de Canarias or the renewal of the Instituto Universitario de Bio-Orgánica Antonio González (IUBO-AG).

He internationalized the ULL, as ideologist of CampusÁfrica, whose name he patented, and with the international seminars that have afterwards taken place. He was also responsible of the substitution of the obsolete power generator in the Pharmacy Faculty, which had caused several cuts and even a fire because of its unattended malfunctioning. These and many more actions gave rise to considerable improvements in the ULL.

Eds.: From a more personal point of view, what do you think you have learnt from each other?

V.B.: I don't know what he might have learnt from me, but I do know I have learnt and keep learning from him every day. I have had the good luck and honor of being his friend and I learn every day from his knowledge, his vast culture, the way he works, his good character and his immense respect for everything and everyone, and especially for the University of La Laguna. Of him can be said the best thing that can be said of anyone: he is "a good person". 
Eds.: Just to conclude, how would you briefly summarize Prof. Gómez Solinno's career?

V.B.: He is an exceptional man who has developed a brilliant career at university. He was Director of his Department, Dean of the Faculty of Philology, Vice rector and Rector. He has created and contributed significantly to create centers and research institutes; he has made the University of La Laguna accessible and productive for the Canarian society; he has collaborated and continues collaborating with projects for the development of science and culture in different countries in our vicinity.

People like him do enrich our University.

Eds.: In and out of the academic world, we need more people like you two. Thanks for the time you have kindly given us to answer these questions. 